\title{
Microbial communities associated with the black morel Morchella sextelata cultivated in greenhouses
}

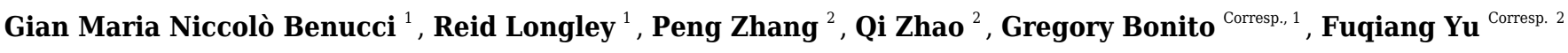 \\ 1 Plant Soil and Microbial Sciences, Michigan State University, East Lansing, Michigan, United States \\ ${ }^{2}$ Key Laboratory for East Asia Biodiversity and Biogeography, Kunming Institute of Botany, Chinese Academy of Sciences, Yunnan, China \\ Corresponding Authors: Gregory Bonito, Fuqiang Yu \\ Email address: bonito@msu.edu, fqyu@mail.kib.ac.cn
}

Morels (Morchella spp.) are iconic edible mushrooms with a long history of human consumption. Some microbial taxa are hypothesized to be important in triggering the formation of morel primordia and development of fruiting bodies, thus, there is interest in the microbial ecology of these fungi. To identify and compare fungal and prokaryotic communities in soils where Morchella sextelata is cultivated in outdoor greenhouses, ITS and 16S rDNA high throughput amplicon sequencing and microbiome analyses were performed. Pedobacter, Pseudomonas, Stenotrophomonas, and Flavobacterium were found to comprise the core microbiome of $M$. sextelata ascocarps. These bacterial taxa were also abundant in the soil beneath growing fruiting bodies. Twenty-nine bacterial taxa were found to be statistically associated to Morchella fruiting bodies. Bacterial community network analysis revealed high modularity with some 16S rDNA OTU clusters living in specialized fungal niches (e.g. pileus, stipe). Other fungi dominating the soil mycobiome beneath morels included Morchella, Phialophora, and Mortierella. This research informs understanding of microbial indicators and potential facilitators of Morchella ecology and fruiting body production. 
1 Microbial communities associated with the black morel Morchella sextelata cultivated in

2 greenhouses

3

4 Gian Maria Niccolò Benucci ${ }^{{ }^{\star}}$, Reid Longley ${ }^{1^{\star}}$, Zhang Peng ${ }^{2}$, Zhao Qi ${ }^{2}$, Gregory Bonito ${ }^{1}$,

$5 \quad$ Fuqiang $\mathrm{Yu}^{2}$

6

$7 \quad{ }^{1}$ Michigan State University, East Lansing MI, 48824, USA

82 Key Laboratory for East Asia Biodiversity and Biogeography, Kunming Institute of Botany,

9 Chinese Academy of Sciences, Yunnan, China

10

11 ( $)$ Corresponding Authors Contact:

12 Fuqiang Yu (outdoor morel cultivation requests) - fqyu@mail.kib.ac.cn

13 Gregory Bonito (all other requests) - bonito@msu.edu

$14\left(^{*}\right)$ these authors equally contributed to this study.

15

ORCID ID - Benucci GMN https://orcid.org/0000-0003-1589-947X

17 ORCID ID - Bonito G https://orcid.org/0000-0002-7262-8978

ORCID ID - Longley R https://orcid.org/0000-0001-7355-0263 


\section{Abstract}

27 Morels (Morchella spp.) are iconic edible mushrooms with a long history of human consumption.

28 Some microbial taxa are hypothesized to be important in triggering the formation of morel 29 primordia and development of fruiting bodies, thus, there is interest in the microbial ecology of 30 these fungi. To identify and compare fungal and prokaryotic communities in soils where Morchella 31 sextelata is cultivated in outdoor greenhouses, ITS and 16S rDNA high throughput amplicon 32 sequencing and microbiome analyses were performed. Pedobacter, Pseudomonas, 33 Stenotrophomonas, and Flavobacterium were found to comprise the core microbiome of $M$. 34 sextelata ascocarps. These bacterial taxa were also abundant in the soil beneath growing fruiting 35 bodies. Twenty-nine bacterial taxa were found to be statistically associated to Morchella fruiting 36 bodies. Bacterial community network analysis revealed high modularity with some 16S rDNA OTU 37 clusters living in specialized fungal niches (e.g. pileus, stipe). Other fungi dominating the soil mycobiome beneath morels included Morchella, Phialophora, and Mortierella. This research informs understanding of microbial indicators and potential facilitators of Morchella ecology and fruiting body production.

Keywords: microbiome, CONSTAX, USEARCH, amplicon sequencing, Pedobacter, microbial ecology, morel cultivation

44

45

46

47 


\section{Introduction}

Morels (Morchella spp.) are an iconic genus of edible mushrooms that are distributed

54 across the Northern hemisphere (O'Donnell et al., 2011). Morels have a long history of use in

55 Europe, and are sought after in North America and Asia. They remain an economically

56 important culinary mushroom today, and are commercially harvested in the springtime when

57 they fruit naturally (Obst \& Brown, 2000; Pilz et al., 2007). For example, in western North

58 America, morels have been estimated to contribute $\$ 5-10$ million to the economy through direct

59 sales (Pilz et al., 2007).

60 Morchella is a species-diverse genus. Classical taxonomic treatments of Morchella

61 based on morphological characters are complicated by the extreme variation in macro-

62 characters (Richard et al., 2015). Recent efforts have reconstructed the phylogeny and biogeographic history of this genus with multiple genetic loci and have helped to stabilize the taxonomy of Morchella (O'Donnell et al., 2011; Du et al., 2012; Richard et al., 2015). From these studies, over 66 phylogenetic species of Morchella are recognized and shown to belong to three clades: the Elata clade (black morels), the Esculenta clade (yellow morels) and the Rufobrunnea clade (garden morels) (Taskin et al., 2012; Richard et al., 2015). Most morel species are confined geographically to particular continents and regions (O'Donnell et al., 2011), yet, a few species such as $M$. rufobrunnea and $M$. importuna appear to be more widely distributed, perhaps through recent human-mediated transport and long-distance dispersal

71 (Elliott et al., 2014).

While attempts to cultivate morels have been ongoing for decades (Costantin, 1936), methods remained elusive until the 1980s, when protocols for cultivating morels indoors were

74 devised and patented (Ower, 1982; Ower, Mills \& Malachowski, 1986, 1989). Recently, methods

75 for cultivating black morels (Elata clade) in soils under greenhouse environments were

76 developed in China, leading to a significant increase in morel production. Morels are cultivated

77 in non-axenic soils by planting fertile spawn in the soil, and feeding the mycelium with 
78 79 80

exogenous nutrient bags once it emerges from the soil (Guo et al., 2016; He et al., 2017; Liu et al., 2018a). However, as with other agronomic crops there is variability in production, and problems with diseases may occur during production (Guo et al., 2016; He et al., 2017; Liu et al., 2018a). Bacteria are thought to be responsible for the promotion of primordia differentiation and ascocarp growth, and may help suppress diseases (Liu et al., 2017). Consequently, there is interest in understanding the microbial ecology of morels during their cultivation to improve production and to improve diseases detection and management.

A series of bipartite lab experiments indicate that the bacterium Pseudomonas putida can stimulate sclerotium formation of morel isolates (Pion et al., 2013). This association was demonstrated to benefit Morchella's carbon status. A more recent study found that bacteria belonging to Proteobacteria, Chloroflexi, Bacteroides, Firmicutes, Actinobacteria, Acidobacteria and Nitrospirae were associated with soils of outdoor morel cultivation systems (Liu et al., 2017). Liu te al., 2017 showed that the soil bacterial communities, as well as morel yields, were influenced by variations in trace elements such as $\mathrm{Fe}, \mathrm{Zn}, \mathrm{Mn}$ and their complexes. At genus level Pseudomonas, Geobacter and Rhodoplanes were the most predominant detected overall, with Pseudomonas having the highest abundance in the control group, Rhodoplanes dominated in the single-element groups ( $\mathrm{Zn}, \mathrm{Fe}$ and $\mathrm{Mn})$ and Geobacter were lower in the control group than in most experimental groups.

Consequently, it was hypothesized that distinct bacterial consortia associated with morel growth stage and fruiting bodies would be detected. It is expected that this would include Pseudomonas, which has been found to be a beneficial associate of morels previously (Pion et al., 2013), as well as other taxa (Pion et al., 2013). It is also hypothesized that fungal pathogenic lineages may be detected, since greenhouses were dominated by a single cultivated species (M. sextellata). To test these hypotheses, high throughput amplicon sequencing was used to assess fungal (ITS rDNA) and prokaryotic (16S rDNA) communities from an outdoor morel 
103 cultivation environment. This study provides in-depth characterizations of fungal and prokaryotic

104 communities associated with Morchella sextelata and the soils beneath their fruiting bodies.

105

106 Methods

107 Sampling microbial communities associated with morel fruiting bodies and substrates

$108 \quad$ Morel fruiting bodies and soils beneath growing morels were sampled from a high-tunnel

109 greenhouse in Caohaizi Village, Xundian County, Kunming City, Yunnan Province, China,

110 where the black morel M. sextelata was being cultivated. The site is situated $1950 \mathrm{~m}$ in

111 elevation. The pileus and stipe from 5 mature $(>10 \mathrm{~cm})$ and 5 immature $(<1 \mathrm{~cm})$ fruiting bodies

112 were sampled by placing a piece of tissue roughly $1 \mathrm{~cm}^{2}$ in size into CTAB $4 \mathrm{X}$ buffer with a

113 flame sterilized razor. Approximately $2 \mathrm{~cm}^{3}$ of soil was also sampled from directly below each

114 morel fruiting body. Soils were dried completely with silica beads and were kept on silica until

115 processing (described below). In total, microbial analyses were performed on 20 samples, $10 \mathrm{M}$.

116 sextelata ascocarps (5 young and 5 mature), and 10 soils beneath the ascocarps, which were

117 analyzed for both bacterial (16S rDNA) and fungal (ITS rDNA) communities. Bacterial

118 communities were determined for 10 morel ascocarps, including pileus $(n=10 ; 5$ immature, $n=5$

119 mature) and stipe ( $\mathrm{n}=10 ; 5$ immature, $n=5$ mature $)$ tissues.

120

121

Molecular methods

122

DNA was extracted from $\sim 0.5 \mathrm{~g}$ of dried and homogenized soils with the PowerMag ${ }^{\circledR}$

123

Soil DNA Isolation Kit (Qiagen, Carlsbad, CA) following manufacturer's recommendations. Morel

124 tissues and were ground with a sterile micro pestle and then extracted using standard

125 chloroform extraction protocol (Trappe et al. 2010). Extracted DNA was amplified using

126 DreamTaq Green DNA Polymerase (ThermoFisher Scientific, USA) with the following primer

127 sets: ITS1f-ITS4 for Fungi and 515F-806R for Bacteria and Archaea, following a protocol based

128 upon the use of frameshift primers as described by Chen and colleagues (Lundberg et al., 2013;

Peer] reviewing PDF | (2019:05:38095:2:0:NEW 16 Aug 2019) 
129 Chen et al., 2018). PCR products were stained with ethidium bromide, separated through gel 130 electrophoresis, and imaged under UV light. Amplicon concentrations were normalized with the

131 SequalPrep Normalization Plate Kit (ThermoFisher Scientific, USA) and pooled. Amplicons were 132 then concentrated 20:1 with Amicon Ultra 0.5 mL 50K filters (EMD Millipore, Germany) and 133 purified with Agencourt AMPure XP magnetic beads (Beckman Coulter, USA). A synthetic mock 134 community with 12 taxa and 4 negative (no DNA added) controls was included to assess 135 sequencing quality (Palmer et al., 2018). Amplicons were then sequenced on an Illumina MiSeq 136 analyzer using the v3 600 cycles kit (Illumina, USA). Sequence reads have been submitted to 137 NCBI SRA archive under the accession number PRJNA510627.

Bioinformatic analyses

140 Sequence quality was evaluated for raw forward and reverse Illumina ITS and 16S reads with FastQC (http://www.bioinformatics.babraham.ac.uk/projects/fastqc/). Selected reads were demultiplexed in QIIME according to sample barcodes (Caporaso et al., 2010). Forward reads were then cleaned from the Illumina adapters and sequencing primers with Cutadapt (Martin, 144 2011), quality filtered, trimmed to equal length (Edgar \& Flyvbjerg, 2015; Edgar, 2016), dereplicated, removed from singleton sequences and clustered into operational taxonomic units (OTUs) based on $97 \%$ similarity following the UPARSE algorithm (Edgar, 2013). Taxonomy assignments were performed in QIIME with the RDP Naïve Bayesian Classifier (Wang et al., 2007) using the Greengenes database (DeSantis et al., 2006) version gg_13_8 for 16S rDNA, and with CONSTAX (Gdanetz et al., 2017) based on the UNITE fungal ITS rDNA sequence database version 7.1 2016-08-22 (Kõljalg et al., 2005) (Fig. S1).

Statistical analyses

The otu_table.biom (McDonald et al., 2012) with embedded taxonomy classifications and metadata.txt files for each marker gene were imported into the $\mathrm{R}$ statistical environment for 
155 analysis (R Core Team 2017). Before proceeding with analyses, otu_table.biom files were 156 quality filtered removing OTUs with less than 10 total sequences (Lindahl et al., 2013; Oliver, 157 Callaham \& Jumpponen, 2015). OTUs that appeared in the negative controls (i.e. contaminants) 158 were removed across all samples when $\geq 10$ reads were present in any single control.

159 Observed OTU richness (S) (Simpson, 1949), Shannon's diversity index (Hill, 1973), and 160 Evenness (Kindt \& Coe, 2005) were used as a-diversity metrics. The Shannon index $(\mathrm{H})$ was

161 calculated as $H=-\sum_{i=1}^{R} p_{i} \ln p_{i}$ where $p_{i}$ the proportion of individuals belonging to the $i$ species in 162 the dataset, while the OTU evenness $(E)$ was calculated as $E=\frac{H}{\ln (S)}$ where $H$ is the Shannon 163 diversity index and $S$ the observed OTU richness. Diversity indexes were with the "specnumber" 164 and "diversity" functions in R package vegan (Oksanen et al., 2019) and with the function 165 "diversityresult" in the package BiodiversityR (Kindt \& Coe, 2005). After assessing for data 166 normality and homogeneity of variances significant differences between mean alpha-diversity 167 measures were found with ANOVA and Tukey's tests. Rarefaction curves were used to assess 168 OTU richness from the results of sampling (Fig. S2, S3). To avoid biases and data loss in some 169 groups of samples due to inherent variations in alpha-diversity in soils compared to morels, OTUs were normalized using the R package metagenomeSeq before calculating $\beta$-diversity

171 (Paulson et al., 2013). Principal coordinate decomposition (PCoA) was used to investigate 172 community $\beta$-diversity with the function "ordinate" from the phyloseq package (McMurdie \& 173 Holmes, 2013). Diversity patterns were then tested for statistical differences across sites in the 174 vegan R package with the PERMANOVA function "adonis" and tested for homogeneity of 175 variances with the function "betadisper". OTUs that showed high and significant correlation with 176 sample groups were identified through the function "multipatt" in the indicspecies package (De 177 Cáceres \& Legendre, 2009).

178 To assess co-occurrences among OTUs a bipartite network was produced for the 179 prokaryotic communities with the "spiec.easi" function in the SpiecEasi R package (Kurtz et al., 
180 2015). To build the network, the following parameters were used: lambda.min.ratio=1e-2,

181 nlambda=50, rep. num=99. The network was constructed using the OTUs present in at least 15

182 samples to increase the sensitivity of the analysis. After assessing network stability using the

183 "getStability" function in SpiecEasi, general (i.e., Modularity, Sparsity, Transitivity,) and

184 individual OTUs (i.e., degree, closeness centrality, betweenness centrality, articulation points)

185 network indexes were calculated. The network was visualized with the Fruchterman-Reingold

186 layout with $10^{4}$ permutations as implemented in the igraph R package (Csardi \& Nepusz, 2006).

187 A heatmap showing abundances of prokaryotic OTUs statistically associated with Morchella

188 ascocarps was created using the ComplexHeatmap R package (Gu, Eils \& Schlesner, 2016). All

189 statistical analyses and graphs were performed in R version 3.4.4 (R Core Team, 2018).

190

191 Results

192

High-throughput sequencing results

193 After quality filtering, a total of 215,201 reads were analyzed with an average read depth

194 of 21,520 across 10 samples for the ITS marker and 2,237,810 reads with an average read

195 depth of 74,593 reads across 30 samples for $16 S$ rDNA. After removing contaminants, as well

196 as negative and mock samples, a total of 509 OTUs for fungal communities and 5,169 OTUs for

197 prokaryotic communities were obtained. Our synthetic mock community matched the 12

198 artificial taxa, which were sequenced alongside with the samples. No mock sequences were

199 detected in any other libraries indicating that barcode switching was not an issue in this study.

200

201 Fungal and Prokaryotic communities composition of Morchella sextelata fruiting bodies and

202 associated soils

203 The fungal communities of the Morchella soil substrate were dominated overall by

204 Ascomycota (72.9\%), Mucoromycota (7.1\%), and Basidiomycota (3.4\%). The fungal

205 communities of the substrate beneath the young Morchella ascocarps were dominated by 
206 Morchella sp. (39.0\%), Phialophora sp. (15.6\%), and Mortierella (8.7\%). Under the mature 207 Morchella ascocarps, the same most abundant taxa were detected, but with different relative 208 abundances: Morchella sp. (58.2\%), Phialophora sp. (15.6\%), Mortierella (5.3\%). Relative 209 abundances at family level (Relative abundance > 1\%) for each analyzed sample are also 210 reported in the barplot (Fig. 1A).

211 Differences in community composition associated with pileus, stipe, or soil niches were 212 detected in 16S rDNA communities. A barplot of relative abundances at phylum level (relative 213 abundance $>1 \%$ ) of the prokaryotic communities are shown in Fig. 1B. The whole prokaryotic 214 community was dominated by Bacteroidetes (36.7\%), Proteobacteria $(23.7 \%)$, and

215 Actinobacteria (12.3\%). The prokaryotic communities in the pileus of Morchella ascocarps were 216 dominated by Bacteroidetes (53.3\%) and Proteobacteria (43.9\%). The most abundant genera 217 were Pedobacter (38.7\%), Pseudomonas (28.3\%), and Flavobacterium (10.6\%). In the stipe of 218 Morchella ascocarps the dominant phyla were Bacteroidetes (89.2\%) and Proteobacteria 219 (9.2\%), which included the genera Pedobacter (83.1\%), Flavobacterium (4.9\%), and Pseudomonas (2.4\%). In the soil beneath Morchella ascocarps the dominant prokaryotic phyla were Actinobacteria (26.1\%), Chloroflexi (19.8\%), and Proteobacteria (19.8\%). The most abundant genera were an uncultured bacterium in the Gaiellaceae (6.6\%), an uncultured bacterium in the Ellin6529 clade (6.1\%) and Kaistobacter (3.5\%) (Fig. 1B).

224

Microbial richness and evenness in soils beneath Morchella fruiting bodies Significant differences $(p \leq 0.05)$ in OTU richness of the prokaryotic community were found between soil, stipe, and pileus samples (Table 1). The soil compartment showed almost 10-fold higher richness than was present in Morchella pileus or stipe compartments. Similar trends were true for both Evenness $(\mathrm{E})$ and Shannon index $(\mathrm{H})$ diversity measurements. No differences were found when average alpha-community measures were compared between 
231 young and mature morel samples. Fungal alpha diversity trended to be slightly higher in the 232 samples of the young Morchella, but this was not statistically significant (Table 1).

233

234 Fungal and prokaryotic community $\beta$-diversity in Morchella samples

Principal coordinate analysis (PCoA) ordination graphs performed on the $16 \mathrm{~S}$ rDNA data show that the difference between the soil from pileus and stipe prokaryotic communities explained the variance obtained in the first axis (49.9\%), while differences between pileus and stipe samples are evident in the second axis (18.3\%) (Fig. 2A). PCoA ordination graphs performed on ITS soil data show that the variance of the first axis $(66.3 \%)$ is due to differences between samples collected under mature compared to young Morchella fruiting bodies (Fig. 2B). Variation obtained for the second axis ( $8.8 \%)$ is due to the high heterogeneity (See below) of the samples collected under young $M$. sextelata fruiting bodies. PERMANOVA analysis of the $16 S$ dataset show that there was a significant effect of the maturity stage of Morchella samples on the prokaryotic communities (Table 2). The PERMANOVA analysis of the ITS dataset show that there was a significant effect of maturity stage of $M$. sextelata fruiting bodies on the soil fungal communities (Table 2 ) that was not due to sample group dispersion (Fig. S5).

Indicator species and intersections between stage and site

Several prokaryotic OTUs were significantly associated with the pileus, stipe, or associated soil (and combination of them) portions of $M$. sextelata fruiting bodies (Table S1). A heatmap of the OTUs associated with Morchella fruiting bodies (i.e. associated to pileus, stipe, stipe and pileus, soil and pileus, stipe and soil) is provided in Fig. 3. Two OTUs were statistically associated to Morchella's pileus: Corynebacterium sp. and Pseudanabaena sp. Two OTUs were also associated to the Morchella stipe. Granulicatella sp. and an unidentified OTU in Coxiellaceae. All other OTUs reported in the heatmap were associated to two different groups. 
256

257

258

259

260

261

262

263

264

265

266

267

268

269

270

271

272

273

274

275

276

277

278

279

280

281

Among these OTUs, one specific Pedobacter sp.1 was associated to both pileus and stipe and was more abundant in these two compartments than it was in the soils.

Venn diagrams show that soil samples contained a high number of unique prokaryotic OTUs $(3,239)$ compared to pileus (63), and stipe (34) samples (Fig. 4A) in contrast to what was shared among them (789). Most bacterial OTUs detected in Morchella fruiting bodies were found in young and mature fruiting bodies (4644), with only 194 and 331 uniquely present in young or mature samples, respectively. In the fungal communities, mature and young morel soils shared 396 OTUs, while 33 and 80 OTUs were only present in mature or young specimen, respectively (Fig. 4C).

\section{Network analysis}

The bipartite network (140 vertex, 199 edges, stability= 0.044$)$ that was obtained is a sparse network (Fig. 5A, B), having a low number of possible edges (sparsity $\approx 2 \%$ ). The network showed low transitivity $(\approx 0.15)$ which is a measure of the probability that the adjacent

vertices of a vertex are connected. The network showed high modularity $(\approx 0.5)$ which measures the division into subgraphs (i.e., communities or modules) in which vertex (i.e., OTUs) are more interconnected together than with the rest of the network. A total of 45 modules were identified, with the first 5 modules containing $40 \%$ of the total OTUs: Module 1 contained 29 OTUs; Module 2 contained 9 OTUs; Module 3 contained 8 OTUs; Module 4 contained 6 OTUs; Module 5 contained 5 OTUs. Seventeen modules were composed of 1 single OTU (Fig. 5 A). Several modules were peripheral and negatively connected (edge weight $\max =0.34, \min =-0.20$ ) to other modules. Module 5 contained two indicator OTUs identifies for the pileus and stipe niche. Most of the indicator taxa for the stipe and soil environments were in single OTU modules (See Fig. 3 for taxonomic position), disconnected from the main network. Taxonomic classifications at phylum level of each OTU in the network is shown in Fig. 5B. Proteobacteria, Acidobacteria, and Gemmatimonadetes were dominant in the first five modules (Fig. 5C). Interestingly, 
282 archaeal OTUs in the Euryarchaeota, Crenarchaeota were also present in the network. In 283 addition to identifying nodes with high degree (number of connections), some OTUs were 284 identified as articulation points, node whose removal disconnects the network (e.g. OTU_2352). 285

\section{Discussion}

Black morels are cultivated in greenhouse conditions in non-sterilized soils (Liu et al., 2018a). It has been hypothesized that fungi and bacteria living in these substrates may facilitate, or conversely, inhibit developmental transitions and fruiting body development (Liu et al., 2017). Soils where morels are cultivated successfully were highly colonized by Morchella mycelium, especially in soils beneath mature morel fruiting bodies. The morel mycelium inoculated in soils appears to overgrow and potentially exclude other fungal taxa. Regarding prokaryotic communities, Pedobacter, Pseudomonas, Stenotrophomonas, and Flavobacterium were dominate in the microbiome of Morchella sextelata fruiting bodies. The high abundance of Pseudomonas (Proteobacteria) in morel fruiting bodies raises questions concerning their roles in the development of morels, following observations on the occurrence and diversity of bacterial communities on Tuber magnatum during truffle maturation, Pseudomonas putida farming by M. crassipes (Pion et al., 2013), and the abundance of Pseudomonas OTUs in soils where black morels are cultivated in Sichuan, China (Liu et al., 2017).

Strong effects of fungal host identity have been seen on the structure of bacterial communities in other mushroom species (Pent, Põldmaa \& Bahram, 2017). Interestingly, Pseudomonas, Flavobacterium, Janthinobacterium, and Polaramonas were also detected in 304 fruiting bodies of Pezizales truffle species through 16S rDNA surveys of the fruiting bodies 305 (Benucci \& Bonito, 2016; Splivallo et al., 2019), including, Kalapuya brunnea, which belongs to 306 the Morchellaceae family (Trappe, Trappe \& Bonito, 2010). Selective filtering of bacterial 307 communities by the fungal host has also been shown for other fungi, such as Tuber (Barbieri et 
308 al., 2005, 2007; Antony-Babu et al., 2014; Splivallo et al., 2015, 2019; Benucci \& Bonito, 2016;

309 Amicucci et al., 2018), Cantharellus (Kumari, Sudhakara Reddy \& Upadhyay, 2013; Pent,

310 Põldmaa \& Bahram, 2017), Tricholoma (Oh et al., 2018), Agaricus (Rossouw \& Korsten, 2017;

311 Aslani, Harighi \& Abdollahzadeh, 2018), Suillus, Leccinum, Amanita, and Lactarius (Pent,

312 Põldmaa \& Bahram, 2017; Liu et al., 2018b). As reported in Table 3, Proteobacteria are some of

313 the most abundant bacterial genera associated with fruiting bodies of different fungal lineages

314 based on recent published literature.

315 Moreover, the relative abundances of bacterial groups varied between sterile (stipe) and

316 fertile (pileus) tissues of morel mushrooms, as well as from the soil beneath them. For instance,

317 the pileus of Morchella was enriched in Pseudomonas, Stenotrophomonas, and Flavobacteria

318 compared to stipe microbial communities. The stipe was mostly colonized by Pedobacter (83\%)

319 compared to the pileus (39\%) and the soil where it accounted for only $0.4 \%$ of relative

320 abundance of bacteria. OTUs classified as Pedobacter were statistically associated to pileus

321 and stipe tissues and were present in different modules in the microbial network. This indicates

322 that the pileus tissue may recruit a specific set of prokaryotic taxa which are not recruited to the

323 stipe. This is supported by a significant reduction in prokaryotic richness in the pileus and stipe

324 compared to the soils. Of interest, the two tissue types also smelled different. Previous studies

325 have indicated differences in the chemical composition of Amanita pileus and stipes due to

326 metabolite production in the fruiting body (Deja et al., 2014). If similar chemical differences exist

327 between Morchella pileus and stipe, this could offer an explanation for the existence of different

328 prokaryotic communities within distinct tissues of the Morchella fruiting body and the soil

329 beneath them.

330 Morchella pileus, stipes, and soils were also shown to be specific niches for other

331 indicator bacterial taxa. Surprisingly, human and animal (sometimes plant) pathogens such as

332 Corynebacterium, Granulicatella, Streptococcus and Staphylococcus were found exclusively

333 associated to the pileus and/or stipe environment (Collins et al., 2004; Cargill et al., 2012).

Peer] reviewing PDF | (2019:05:38095:2:0:NEW 16 Aug 2019) 
334 These taxa are components of the microbial network associated with Morchella fruiting bodies

335 (Fig. 5), although they were found in peripheral modules that were negatively connected with

336 the main structure. Some other taxa such as Lacibacter (Qu et al., 2009) or Sediminibacterium

337 (Qu, -H. Qu \& -L. Yuan, 2008), which are bacteria common in soil, were also identified as

338 indicator species but were not present in our network.

339 It has been hypothesized that microbes in the soil are necessary for morel fruiting to

340 occur. The role of Pseudomonas in the cultivation of button mushrooms (Agaricus bisporus) has

341 been studied previously, and was shown to increase both yield and primordia formation

342 (Zarenejad, Yakhchali \& Rasooli, 2012; Chen et al., 2013; Pent, Põldmaa \& Bahram, 2017). The

343 relative abundance of Pseudomonas species increased throughout cultivation cycle of Agaricus

344 bisporus and peaked around the time of fruiting (Chen et al., 2013). It was also shown that the

345 presence of specific strains of Pseudomonas putida in Agaricus inoculum increased mushroom

346 yields by as much as 14\% (Zarenejad, Yakhchali \& Rasooli, 2012). Previous research found

347 that $P$. putida stimulates sclerotia formation in Morchella (Pion et al., 2013). These results are

348 consistent with our findings that Pseudomonas are abundant in soils and fruiting bodies of

349 cultivated morels, thus, they may be important in the growth and fruiting of these fungi. Liu et al.,

350 (2017) also demonstrated that Pseudomonas are the most common bacteria overall in soils

351 where morels are cultivated, with the highest abundance in the treatment having the highest

352 yield of morel ascocarps, however, bacterial associated with morel fruiting bodies was not

353 assessed. The effect of Flavobacterium spp. on mushroom fruiting body formation is not well

354 studied, but these bacteria have been shown to be associated with the successful cultivation of

355 Pleurotus ostreatus (Cho et al., 2008). Thus, it is possible that Flavobacterium contribute to the

356 formation of mushroom fruiting bodies.

357 The recruitment of prokaryotic communities by Morchella may occur due to a selection

358 by the fungus for specific taxa, or because it offers a preferential niche for bacterial growth. It is

359 also possible that these two factors act simultaneously. For example, Cantharellus cibarius is 
360 populated by millions of different bacteria that are thought to be existing on fungal exudates

361 including trehalose and mannitol (Rangel-Castro, Danell \& Pfeffer, 2002). Fast growing bacteria

362 that live on fungal-derived nutrients may occupy this niche quickly and may play a role in

363 inhibiting the entry of other bacteria or pathogens (Liu et al., 2018b). Future studies can directly

364 test these hypotheses by assessing the importance of management and specific bacterial taxa

365 on the morel microbiome and fruiting body production.

366

367 Conclusions

368 In conclusion, our work adds further evidence that the fungal host plays a role in the

369 selective recruitment of specific bacterial taxa. Our study found that the Morchella microbiome is

370 consistently comprised of a small community of bacteria, including Pedobacter, Pseudomonas,

371 Stenotrophomonas, and Flavobacteria, which appear to be recruited from the soil and enriched

372 in fungal fruiting body tissues. Among those, Pedobacter was enriched in and significantly

373 associated with the pileus environment in respect to the stipe and soil compartments. Although

374 some of the bacteria groups detected on morels have also been detected in other mushrooms,

375 based on this preliminary study, many microbial taxa may be exclusive to Morchella. The role of

376 host identity may provide predictive explanation for differences between microbiomes of morels

377 and other mushrooms. Future research is warranted to test the function of these bacteria on

378 morel fruitification and management.

379

380 Author Contributions

381 Designing and carrying out experiment: FY, GB, ZQ

382 Sampling and sample processing: FY, GB, RL, ZP

383 Data analysis: GMNB, RL

384 Writing manuscript: GB, GMNB, RL, FY 
386 Authors: Reid Longley = RL, Gian Maria Niccolò Benucci = GMNB; Zhang Peng = ZP; Zhao Qi

$387=\mathrm{ZQ}$; Fuqiang Yu = FY; Gregory Bonito $=\mathrm{GB}$

388

389 Acknowledgements

390 The authors are grateful to Caohaizi Village for use of facilities and allowing and

391 assisting us with sampling in this study. The authors confirm they have no conflicts of interest

392 pertaining to this research.

393

394 References

395

396

397

398

399

400

401

402

403

404

405

406

407

408

409

410

Amicucci A, Barbieri E, Sparvoli V, Gioacchini AM, Calcabrini C, Palma F, Stocchi V, Zambonelli A. 2018. Microbial and pigment profile of the reddish patch occurring within Tuber magnatum ascomata. Fungal biology 122:1134-1141. DOI: 10.1016/j.funbio.2018.07.007.

Antony-Babu S, Deveau A, Van Nostrand JD, Zhou J, Le Tacon F, Robin C, Frey-Klett P, Uroz S. 2014. Black truffle-associated bacterial communities during the development and maturation of Tuber melanosporum ascocarps and putative functional roles. Environmental microbiology 16:2831-2847. DOI: 10.1111/1462-2920.12294.

Aslani MA, Harighi B, Abdollahzadeh J. 2018. Screening of endofungal bacteria isolated from wild growing mushrooms as potential biological control agents against brown blotch and internal stipe necrosis diseases of Agaricus bisporus. Biological Control 119:20-26. DOI: 10.1016/j.biocontrol.2018.01.006.

Barbieri E, Bertini L, Rossi I, Ceccaroli P, Saltarelli R, Guidi C, Zambonelli A, Stocchi V. 2005. New evidence for bacterial diversity in the ascoma of the ectomycorrhizal fungus Tuber borchii Vittad. FEMS microbiology letters 247:23-35. DOI: 10.1016/j.femsle.2005.04.027.

Barbieri E, Guidi C, Bertaux J, Frey-Klett P, Garbaye J, Ceccaroli P, Saltarelli R, Zambonelli A, Stocchi V. 2007. Occurrence and diversity of bacterial communities in Tuber magnatum 
411 during truffle maturation. Environmental microbiology 9:2234-2246. DOI: 10.1111/j.1462$412 \quad$ 2920.2007.01338.x.

413 Benucci GMN, Bonito GM. 2016. The Truffle Microbiome: Species and Geography Effects on 414 Bacteria Associated with Fruiting Bodies of Hypogeous Pezizales. Microbial ecology 72:4415 8. DOI: $10.1007 / \mathrm{s} 00248-016-0755-3$.

416 Caporaso JG, Gregory Caporaso J, Kuczynski J, Stombaugh J, Bittinger K, Bushman FD, 417 Costello EK, Fierer N, Peña AG, Goodrich JK, Gordon JI, Huttley GA, Kelley ST, Knights D, 418 Koenig JE, Ley RE, Lozupone CA, McDonald D, Muegge BD, Pirrung M, Reeder J, 419 Sevinsky JR, Turnbaugh PJ, Walters WA, Widmann J, Yatsunenko T, Zaneveld J, Knight R. 2010. QIIME allows analysis of high-throughput community sequencing data. Nature methods 7:335-336. DOI: 10.1038/nmeth.f.303.

Cargill JS, Scott KS, Gascoyne-Binzi D, Sandoe JAT. 2012. Granulicatella infection: diagnosis and management. Journal of medical microbiology 61:755-761. DOI: 10.1099/jmm.0.039693-0.

Chen K-H, Liao H-L, Arnold AE, Bonito G, Lutzoni F. 2018. RNA-based analyses reveal fungal communities structured by a senescence gradient in the moss Dicranum scoparium and the presence of putative multi-trophic fungi. The New phytologist 218:1597-1611. DOI: 10.1111/nph.15092.

Chen S, Qiu C, Huang T, Zhou W, Qi Y, Gao Y, Shen J, Qiu L. 2013. Effect of 1aminocyclopropane-1-carboxylic acid deaminase producing bacteria on the hyphal growth and primordium initiation of Agaricus bisporus. Fungal ecology 6:110-118. DOI: 10.1016/j.funeco.2012.08.003.

Cho YS, Weon HY, Joh JH, Lim JH, Kim KY, Son ES, Lee CS, Cho BG. 2008. Effect of Casing Layer on Growth Promotion of the Edible Mushroom Pleurotus ostreatus. Mycobiology 36:40-44. DOI: 10.4489/MYCO.2008.36.1.040.

Collins MD, Hoyles L, Foster G, Falsen E. 2004. Corynebacterium caspium sp. nov., from a 

microbiology 54:925-928. DOI: 10.1099/ijs.0.02950-0.

Costantin J. 1936. La culture de la morille et sa forme conidienne. In: Annales des Sciences naturelles et botaniques. 249-252.

441 Csardi G, Nepusz T. 2006. The igraph software package for complex network research. $442 \quad$ InterJournal, Complex Systems.

443 De Cáceres M, Legendre P. 2009. Associations between species and groups of sites: indices $444 \quad$ and statistical inference. Ecology 90:3566-3574.

445 Deja S, Wieczorek PP, Halama M, Jasicka-Misiak I, Kafarski P, Poliwoda A, Młynarz P. 2014.

446 Do differences in chemical composition of stem and cap of Amanita muscaria fruiting 447 bodies correlate with topsoil type? PloS one 9:e104084. DOI:

$448 \quad$ 10.1371/journal.pone.0104084.

449 DeSantis TZ, Hugenholtz P, Larsen N, Rojas M, Brodie EL, Keller K, Huber T, Dalevi D, Hu P, 450 Andersen GL. 2006. Greengenes, a chimera-checked 16S rRNA gene database and DOI: 10.1128/AEM.03006-05.

Du X-H, Zhao Q, Yang ZL, Hansen K, Taskin H, Büyükalaca S, Dewsbury D, Moncalvo J-M, 2012. How well do ITS rDNA sequences differentiate species of true morels (Morchella)? Mycologia 104:1351-1368. DOI: 10.3852/12-056.

Edgar RC. 2013. UPARSE: highly accurate OTU sequences from microbial amplicon reads. Nature methods 10:996-998. DOI: 10.1038/nmeth.2604.

Edgar R. 2016. UCHIME2: improved chimera prediction for amplicon sequencing. DOI: 10.1101/074252.

461 Edgar RC, Flyvbjerg H. 2015. Error filtering, pair assembly and error correction for nextgeneration sequencing reads. Bioinformatics $31: 3476-3482$. DOI: 
10.1093/bioinformatics/btv401.

464 Elliott TF, Bougher NL, O’Donnell K, Trappe JM. 2014. Morchella australiana sp. nov., an 465 apparent Australian endemic from New South Wales and Victoria. Mycologia 106:113-118. 466 DOI: 10.3852/13-065.

467 Gdanetz K, Benucci GMN, Vande Pol N, Bonito G. 2017. CONSTAX: a tool for improved 468 taxonomic resolution of environmental fungal ITS sequences. BMC bioinformatics 18:538. 469 DOI: 10.1186/s12859-017-1952-x.

470 Gu Z, Eils R, Schlesner M. 2016. Complex heatmaps reveal patterns and correlations in 471 multidimensional genomic data. Bioinformatics 32:2847-2849. DOI:

$472 \quad$ 10.1093/bioinformatics/btw313.

473 Guo MP, Chen K, Wang GZ, Bian YB. 2016. First Report of Stipe Rot Disease on Morchella 474 importuna Caused by Fusarium incarnatum - F. equiseti Species Complex in China. Plant 475 disease 100:2530-2530. DOI: 10.1094/PDIS-05-16-0633-PDN.

476 He X-L, Peng W-H, Miao R-Y, Tang J, Chen Y, Liu L-X, Wang D, Gan B-C. 2017. White mold 477 on cultivated morels caused by Paecilomyces penicillatus. FEMS microbiology letters 364. $478 \quad$ DOI: $10.1093 /$ femsle/fnx037.

479 Hill MO. 1973. Diversity and Evenness: A Unifying Notation and Its Consequences. Ecology $480 \quad 54: 427-432$. DOI: $10.2307 / 1934352$.

481 Kindt R, Coe R. 2005. Tree Diversity Analysis: A Manual and Software for Common Statistical 482 Methods for Ecological and Biodiversity Studies. World Agroforestry Centre.

483 Kõljalg U, Larsson K-H, Abarenkov K, Henrik Nilsson R, Alexander IJ, Eberhardt U, Erland S, 484 Høiland K, Kjøller R, Larsson E, Pennanen T, Sen R, Taylor AFS, Tedersoo L, Vrålstad T. 485 2005. UNITE: a database providing web-based methods for the molecular identification of 486 ectomycorrhizal fungi. The New phytologist 166:1063-1068. DOI: 10.1111/j.1469$487 \quad$ 8137.2005.01376.x.

488 Kumari D, Sudhakara Reddy M, Upadhyay RC. 2013. Diversity of cultivable bacteria associated 
with fruiting bodies of wild Himalayan Cantharellus spp. Annals of Microbiology 63:845853. DOI: $10.1007 / \mathrm{s} 13213-012-0535-3$.

491 Kurtz ZD, Müller CL, Miraldi ER, Littman DR, Blaser MJ, Bonneau RA. 2015. Sparse and 492 compositionally robust inference of microbial ecological networks. PLoS computational 493 biology 11:e1004226. DOI: 10.1371/journal.pcbi.1004226.

494 Lindahl BD, Henrik Nilsson R, Tedersoo L, Abarenkov K, Carlsen T, Kjøller R, Kõljalg U, 495 Pennanen T, Rosendahl S, Stenlid J, Kauserud H. 2013. Fungal community analysis by 496 high-throughput sequencing of amplified markers - a user's guide. The New phytologist 199:288-299. DOI: 10.1111/nph.12243.

498

499

500

501

502

503

504

505

506

507

508

509

510

511

512

513

514

Liu Q, Liu H, Chen C, Wang J, Han Y, Long Z. 2017. Effects of element complexes containing Fe, $\mathrm{Zn}$ and Mn on artificial morel's biological characteristics and soil bacterial community structures. PloS one 12:e0174618. DOI: 10.1371/journal.pone.0174618.

Liu Q, Ma H, Zhang Y, Dong C. 2018a. Artificial cultivation of true morels: current state, issues and perspectives. Critical reviews in biotechnology 38:259-271. DOI:

$$
\text { 10.1080/07388551.2017.1333082. }
$$

Liu Y, Sun Q, Li J, Lian B. 2018b. Bacterial diversity among the fruit bodies of ectomycorrhizal and saprophytic fungi and their corresponding hyphosphere soils. Scientific reports 8:11672. DOI: 10.1038/s41598-018-30120-6.

Lundberg DS, Yourstone S, Mieczkowski P, Jones CD, Dangl JL. 2013. Practical innovations for high-throughput amplicon sequencing. Nature methods 10:999-1002. DOI: 10.1038/nmeth.2634.

Martin M. 2011. Cutadapt removes adapter sequences from high-throughput sequencing reads. EMBnet.journal 17:10. DOI: 10.14806/ej.17.1.200.

McDonald D, Clemente JC, Kuczynski J, Rideout JR, Stombaugh J, Wendel D, Wilke A, Huse S, Hufnagle J, Meyer F, Knight R, Caporaso JG. 2012. The Biological Observation Matrix (BIOM) format or: how I learned to stop worrying and love the ome-ome. GigaScience 1:7. 
DOI: $10.1186 / 2047-217 X-1-7$.

516 McMurdie PJ, Holmes S. 2013. phyloseq: An R Package for Reproducible Interactive Analysis

517 and Graphics of Microbiome Census Data. PloS one 8:e61217. DOI:

$518 \quad$ 10.1371/journal.pone.0061217.

519 Obst J, Brown W. 2000. Feasibility of a morel mushroom harvest in the Northwest Territories.

$520 \quad$ Government of the Northwest Territories.

521 O'Donnell K, Rooney AP, Mills GL, Kuo M, Weber NS, Rehner SA. 2011. Phylogeny and 522 historical biogeography of true morels (Morchella) reveals an early Cretaceous origin and 523 high continental endemism and provincialism in the Holarctic. Fungal genetics and biology: $524 \quad F G \& B$ 48:252-265.

525 Oh S-Y, Kim M, Eimes JA, Lim YW. 2018. Effect of fruiting body bacteria on the growth of 526 Tricholoma matsutake and its related molds. PloS one 13:e0190948. DOI:

$527 \quad$ 10.1371/journal.pone.0190948.

528 Oksanen J, Guillaume Blanchet F, Friendly M, Kindt R, Legendre P, McGlinn D, Minchin PR, 529 O’Hara RB, Simpson GL, Solymos P, Stevens MHH, Szoecs E, Wagner H. 2019. vegan: 530 Community Ecology Package. R package version 2.5-4.

531 Oliver AK, Callaham MA, Jumpponen A. 2015. Soil fungal communities respond compositionally 532 to recurring frequent prescribed burning in a managed southeastern US forest ecosystem. 533 Forest ecology and management 345:1-9. DOI: 10.1016/j.foreco.2015.02.020.

534 Ower R. 1982. Notes on the Development of the Morel Ascocarp: Morchella Esculenta. 535 Mycologia 74:142-144. DOI: 10.1080/00275514.1982.12021480.

536 Ower RD, Mills GL, Malachowski JA. 1986. Cultivation of Morchella.

537 Ower RD, Mills GL, Malachowski JA. 1989. Cultivation of Morchella. US Patent 4,866,878.

538 Palmer JM, Jusino MA, Banik MT, Lindner DL. 2018. Non-biological synthetic spike-in controls 539 and the AMPtk software pipeline improve mycobiome data. PeerJ 6:e4925. DOI:

$540 \quad 10.7717 /$ peerj.4925. 
541 Paulson JN, Stine OC, Bravo HC, Pop M. 2013. Differential abundance analysis for microbial 542 marker-gene surveys. Nature methods 10:1200-1202. DOI: 10.1038/nmeth.2658.

543 Pent M, Põldmaa K, Bahram M. 2017. Bacterial Communities in Boreal Forest Mushrooms Are 544 Shaped Both by Soil Parameters and Host Identity. Frontiers in microbiology 8:836. DOI: $545 \quad$ 10.3389/fmicb.2017.00836.

546 Pilz D, McLain R, Alexander S, Villarreal-Ruiz L, Berch S, Wurtz TL, Parks CG, McFarlane E, 547 Baker B, Molina R, Others. 2007. Ecology and management of morels harvested from the 548 forests of western North America. Gen. Tech. Rep. PNW-GTR-710. Portland, OR: US 549 Department of Agriculture, Forest Service, Pacific Northwest Research Station. 161 p 710. 550 Pion M, Spangenberg JE, Simon A, Bindschedler S, Flury C, Chatelain A, Bshary R, Job D, 551 Junier P. 2013. Bacterial farming by the fungus Morchella crassipes. Proceedings. 552 Biological sciences / The Royal Society 280:20132242. DOI: 10.1098/rspb.2013.2242. 553 Qu J-H, -H. Qu J, -L. Yuan H. 2008. Sediminibacterium salmoneum gen. nov., sp. nov., a 554 member of the phylum Bacteroidetes isolated from sediment of a eutrophic reservoir. INTERNATIONAL JOURNAL OF SYSTEMATIC AND EVOLUTIONARY MICROBIOLOGY 58:2191-2194. DOI: 10.1099/ijs.0.65514-0.

Qu J-H, -H. Qu J, -L. Yuan H, -S. Yang J, -F. Li H, Chen N. 2009. Lacibacter cauensis gen. nov., sp. nov., a novel member of the phylum Bacteroidetes isolated from sediment of a eutrophic lake. INTERNATIONAL JOURNAL OF SYSTEMATIC AND EVOLUTIONARY MICROBIOLOGY 59:1153-1157. DOI: 10.1099/ijs.0.003475-0.

Rangel-Castro JI, Danell E, Pfeffer PE. 2002. A 13C-NMR study of exudation and storage of carbohydrates and amino acids in the ectomycorrhizal edible mushroom Cantharellus cibarius. Mycologia 94:190-199.

R Core Team. 2018. R: A language and environment for statistical computing. $R$ Foundation for Statistical Computing, Vienna, Austria.

566 Richard F, Bellanger J-M, Clowez P, Hansen K, O’Donnell K, Urban A, Sauve M, Courtecuisse 
567

568

569

570

571

572

573

574

575

576

577

578

579

580

581

582

583

584

585

586

587

588

589

590

591

R, Moreau P-A. 2015. True morels (Morchella, Pezizales) of Europe and North America: evolutionary relationships inferred from multilocus data and a unified taxonomy. Mycologia 107:359-382. DOI: 10.3852/14-166.

Rossouw W, Korsten L. 2017. Cultivable microbiome of fresh white button mushrooms. Letters in applied microbiology 64:164-170. DOI: 10.1111/lam.12698.

Simpson EH. 1949. Measurement of Diversity. Nature 163:688-688. DOI: 10.1038/163688a0.

Splivallo R, Deveau A, Valdez N, Kirchhoff N, Frey-Klett P, Karlovsky P. 2015. Bacteria associated with truffle-fruiting bodies contribute to truffle aroma. Environmental microbiology 17:2647-2660. DOI: 10.1111/1462-2920.12521.

Splivallo R, Vahdatzadeh M, Maciá-Vicente JG, Molinier V, Peter M, Egli S, Uroz S, Paolocci F, Deveau A. 2019. Orchard Conditions and Fruiting Body Characteristics Drive the Microbiome of the Black Truffle Tuber aestivum. Frontiers in Microbiology 10. DOI: 10.3389/fmicb.2019.01437.

Taskin H, Büyükalaca S, Hansen K, O’Donnell K. 2012. Multilocus phylogenetic analysis of true morels (Morchella) reveals high levels of endemics in Turkey relative to other regions of Europe. Mycologia 104:446-461. DOI: 10.3852/11-180.

Trappe MJ, Trappe JM, Bonito GM. 2010. Kalapuya brunnea gen. \& sp. nov. and its relationship to the other sequestrate genera in Morchellaceae. Mycologia 102:1058-1065. DOI: $10.3852 / 09-232$.

Wang Q, Garrity GM, Tiedje JM, Cole JR. 2007. Naive Bayesian classifier for rapid assignment of rRNA sequences into the new bacterial taxonomy. Applied and environmental microbiology 73:5261-5267. DOI: 10.1128/AEM.00062-07.

Zarenejad F, Yakhchali B, Rasooli I. 2012. Evaluation of indigenous potent mushroom growth promoting bacteria (MGPB) on Agaricus bisporus production. World journal of microbiology \& biotechnology 28:99-104. DOI: 10.1007/s11274-011-0796-1.

Peer] reviewing PDF | (2019:05:38095:2:0:NEW 16 Aug 2019) 


\section{Figure Captions}

595 Fig. 1 Stacked bar plots showing fungal families $(\mathrm{A})$ with relative abundance $\geq 1 \%$ detected in 596 soil beneath ascocarps of mature and young Morchella sextelata fruiting bodies, and prokaryotic 597 phyla $(B)$ with relative abundance $\geq 1 \%$ detected in pileus, stipe, and soils beneath ascocarps of 598 mature and young M. sextelata.

599

600 Fig. 2 Principal coordinates analysis plots, using Bray-Curtis dissimilarity matrix, of A)

601 prokaryotic, and B) fungal communities associated with Morchella sextelata.

602

603 Fig. 3 Heatmap of the relative abundances of the 29 indicator taxa significantly associated with 604 Morchella sextelata pileus, stipe, pileus and stipe, pileus and soil, stipe and soil. Samples are 605 ranked according the clustering dendrogram. Blue and white blocks of the top annotation 606 represent samples from young and mature morels, respectively. The side annotation barplot 607 report the square root of the cumulative relative abundance for each OTU across all the 608 samples.

609

610 Fig. 4 Venn diagrams showing core and unique OTUs among different sample groups. A)

611 Prokaryotic communities in pileus, stipe, and soils beneath Morchella sextelata; B) Prokaryotic 612 communities in mature and young ascocarps of $M$. sextelata; C) Fungal communities in mature 613 and young $M$. sextelata ascocarps.

614

615 Fig. 5 Microbial co-occurrence network showing the prokaryotic community structure of 616 Morchella sextelata. Each node (vertex) indicates a single OTU at $97 \%$ sequence similarity.

617 Blue edges indicates positive co-occurrence, red edges indicated negative co-occurrences; A)

618 Network showing indicator species (See in Fig. 3), keystone OTU, and the first top 5 modules. 
619 B) Network showing the taxonomic composition of each node and articulation points. Nodes

620 size is the square root of the relative OTU abundance; C) Barplot showing OTU frequency (OTU

621 richness) and taxonomic composition for the first 5 modules.

622

623 Table Captions

624

625 Table 1 Mean OTU richness (S), Evenness $(E)$, and Shannon diversity index $(H)$ detected in the 626 prokaryotic and fungal communities. Different letters represent statistically significant

627 differences (Tukey test after ANOVA, $p \leq 0.05$ ).

628

629 Table 2 Permutational multivariate analysis of variance (adonis) and multivariate homogeneity 630 of groups dispersions analysis (betadisper) results for both prokaryotic and fungal communities 631 associated with Morchella soil and fruiting bodies. Significant $p$-values at $p \leq 0.05$ are 632 highlighted in bold.

633

634 Table 3 List of the top abundant bacterial genera associated to fungal fruiting bodies of different 635 fungal taxa found in this study and from the literature.

636

\section{Supplementary materials}

638

639 Table S1 List of all the significant ( $p<0.05$ after FDR correction) group indicator OTUs detected 640 in this study.

641

642 Fig S1 Taxonomy output for the ITS dataset produced by the CONSTAX taxonomy tool.

643

644 Fig S2 Rarefaction curves of the prokaryotic 16S rDNA samples. 
645

646 Fig S3 Rarefaction curves of the fungal ITS rDNA samples.

647

648 Fig S4 Plot results of homogeneity of variances (betadisper) of the prokaryotic (A) and fungal

649 (B) communities. From left to right: principal coordinate analysis (PCoA) ordinations according

650 "Origin" and "Stage" (only for prokaryotes) of Bray Curtis dissimilarities and boxplot showing

651 distribution of distances form group centroids.

652 
Figure 1

Figure 1. Stacked bar plots

Stacked bar plots showing fungal families $(\mathrm{A})$ with relative abundance $\geq 1 \%$ detected in soil beneath ascocarps of mature and young Morchella sextelata fruiting bodies, and prokaryotic phyla (B) with relative abundance $\geq 1 \%$ detected in pileus, stipe, and soils beneath ascocarps of mature and young M. sextelata.

A

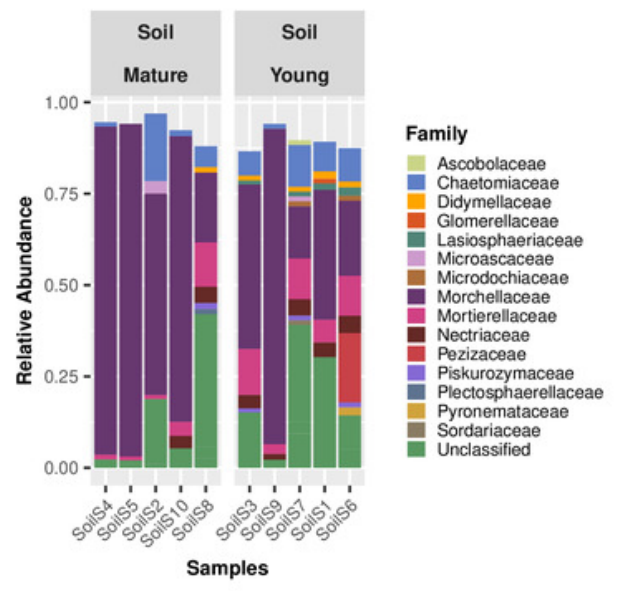

B

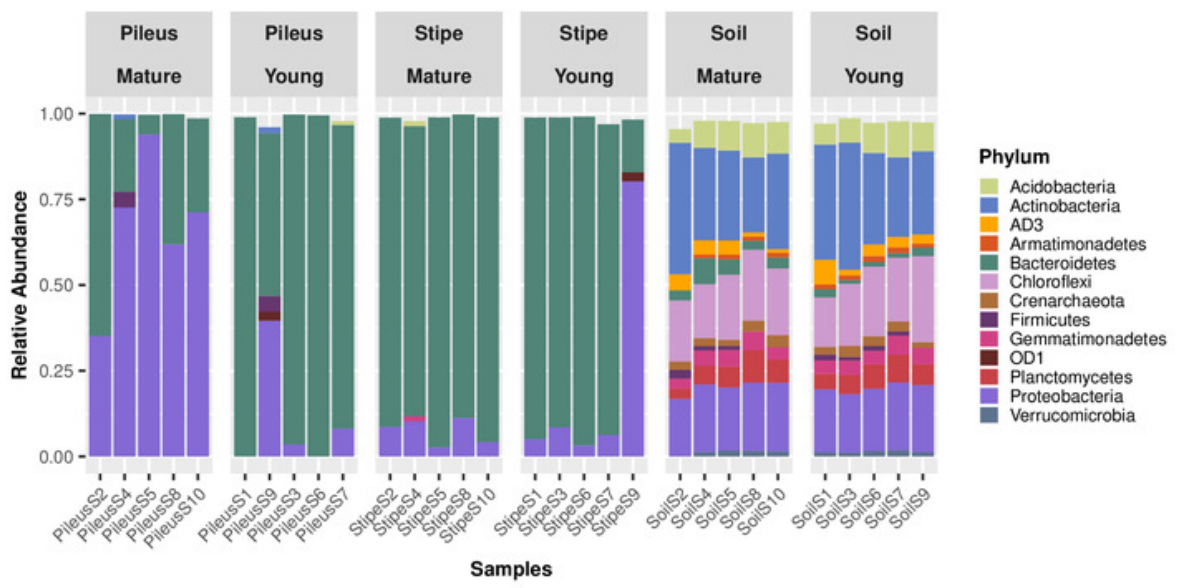


Figure 2

Fig. 2 Principal coordinates analysis plots, using bray-curtis dissimilarity matrix, of fungal A) and prokaryotic B) communities associated with Morchella sextelata.

Fig. 2 Principal coordinates analysis plots, using bray-curtis dissimilarity matrix, of fungal A) and prokaryotic B) communities associated with Morchella sextelata.
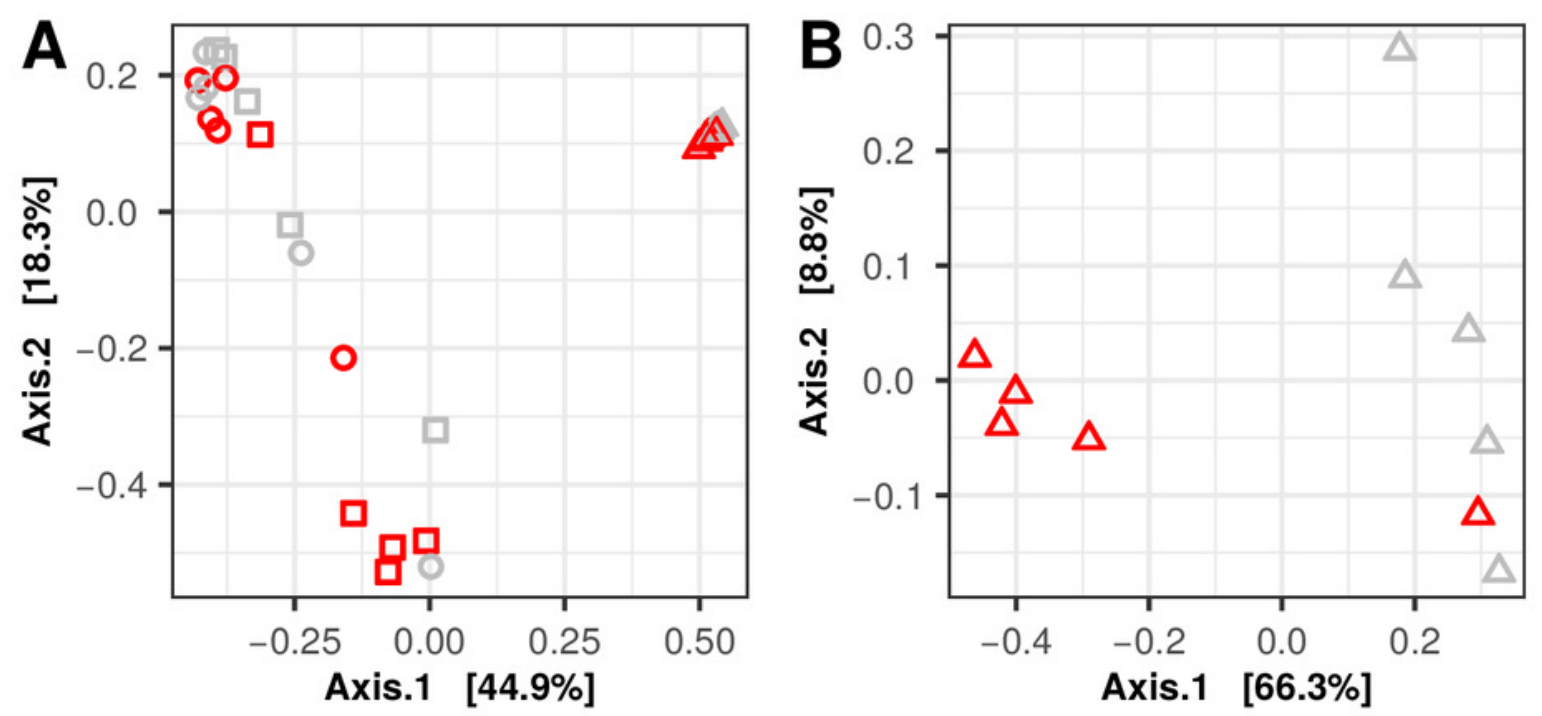

Stage

- Mature

- Young

Origin

口 Pileus

- Stipe

$\Delta$ Soil

Axis.1 [66.3\%] 


\section{Figure 3}

Fig. 3 Heatmap of the relative abundances of the 29 indicator taxa significantly associated with Morchella sextelata pileus, stipe, pileus and stipe, pileus and soil, stipe and soil.

Fig. 3 Heatmap of the relative abundances of the 29 indicator taxa significantly associated with Morchella sextelata pileus, stipe, pileus and stipe, pileus and soil, stipe and soil. Samples are ranked according the clustering dendrogram. Blue and white blocks of the top annotation represent samples from young and mature morels, respectively. The side annotation barplot report the square root of the cumulative relative abundance for each OTU across all the samples.

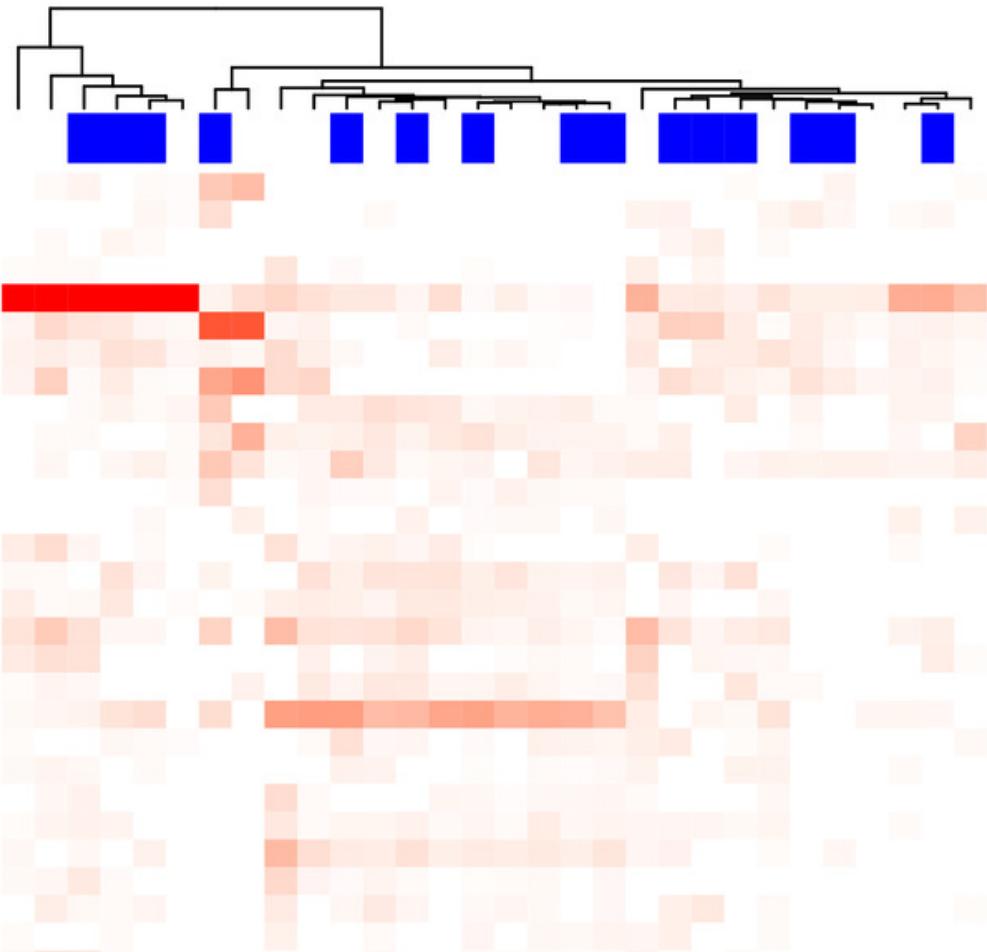

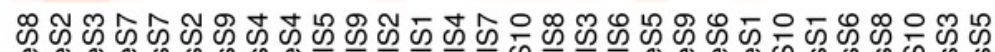
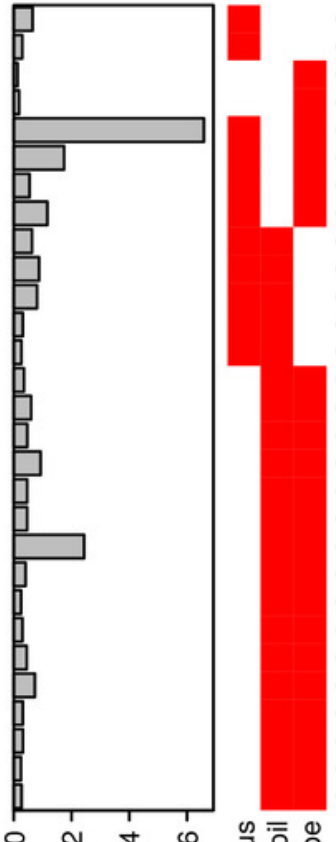

OTU_6929 Corynebacterium sp. OTU_1794 Pseudanabaena sp. OTU 402 Granulicatella sp. OTU 4709 Coxiellaceae OTU_2352 Pedobacter sp. 1 OTU-50 Staphylococcus sp. OTU 5515 Pedobacter sp. 2 OTU 79 Streptococcus sp. OTU_353 Lacibacter cauensis OTU 2182 Agrobacterium sp. OTU 362 Dolichospermum sp. OTU-1272 Rhodococcus sp. OTU-1651 Rhodococcus fascians OTU 254 Sediminibacterium sp. 1 OTU_802 Janthinobacterium sp. OTU_63 Caulobacter sp. OTU 147 Sediminibacterium sp. 2 OTU 5766 Sediminibacterium sp. 3 OTU_645 Pedobacter sp. 3 OTU_320 Gemmatimonadetes I OTU 550 Pirellulaceae OTU 905 Uncultured bacterium 1 OTU_4117 Uncultured bacterium 2 OTU-956 Myxococcales OTU 800 Gemmatimonadetes II OTU 5386 Uncultured bacterium 3 OTU_1876 Uncultured bacterium 4 OTU 4532 Uncultured bacterium 5 OTU_1725 Uncultured bacterium 6

을을.을 屯 
Figure 4

Figure 4. Venn diagrams showing core and unique OTUs among different sample groups.

Fig. 4 Venn diagrams showing core and unique OTUs among different sample groups. A) Prokaryotic communities in pileus, stipe, and soils beneath Morchella sextelata; B) Prokaryotic communities in mature and young ascocarps of $M$. sextelata; C) Fungal communities in mature and young M. sextelata ascocarps.

A

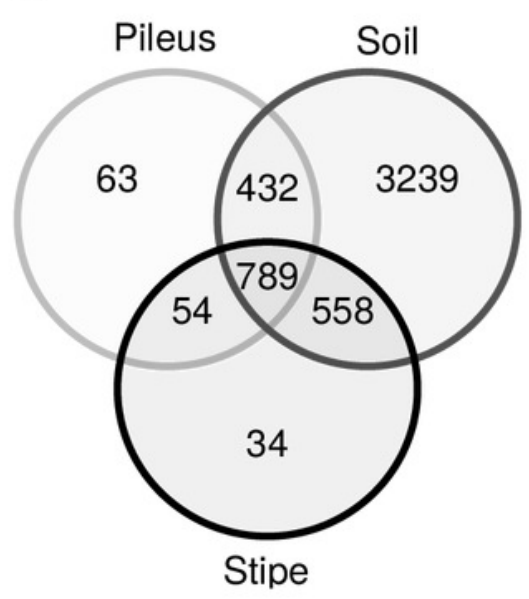

B

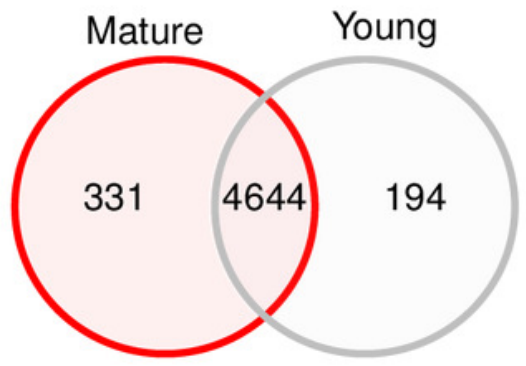

C

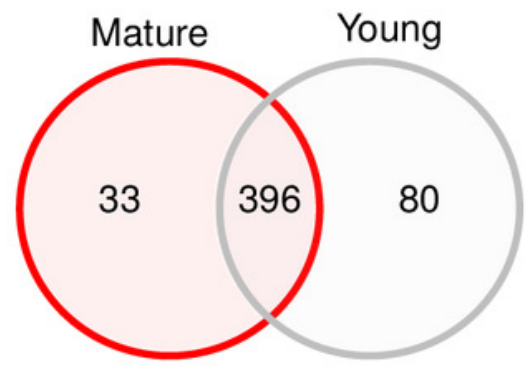




\section{Figure 5}

Fig. 5 Microbial co-occurrence network showing the prokaryotic community structure of Morchella sextelata.

Fig. 5 Microbial co-occurrence network showing the prokaryotic community structure of Morchella sextelata. Each node (vertex) indicates a single OTU at $97 \%$ sequence similarity. Blue edges indicates positive co-occurrence, red edges indicated negative co-occurrences; A) Network showing indicator species (See in Fig. 3), keystone OTU, and the first top 5 modules. B) Network showing the taxonomic composition of each node and articulation points. Nodes size is the square root of the relative OTU abundance; C) Barplot showing OTU frequency (OTU richness) and taxonomic composition for the first 5 modules.

A

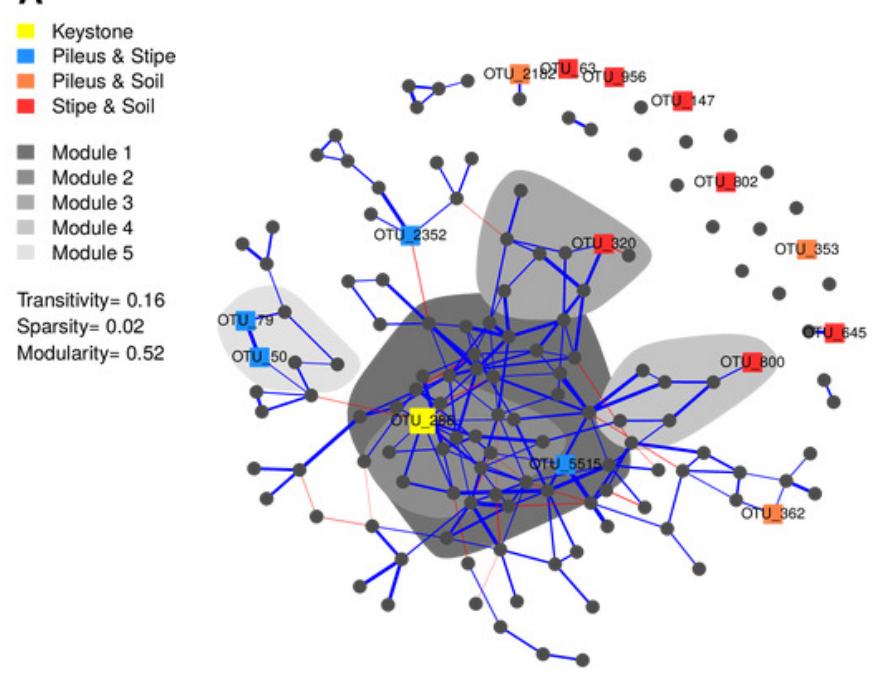

B

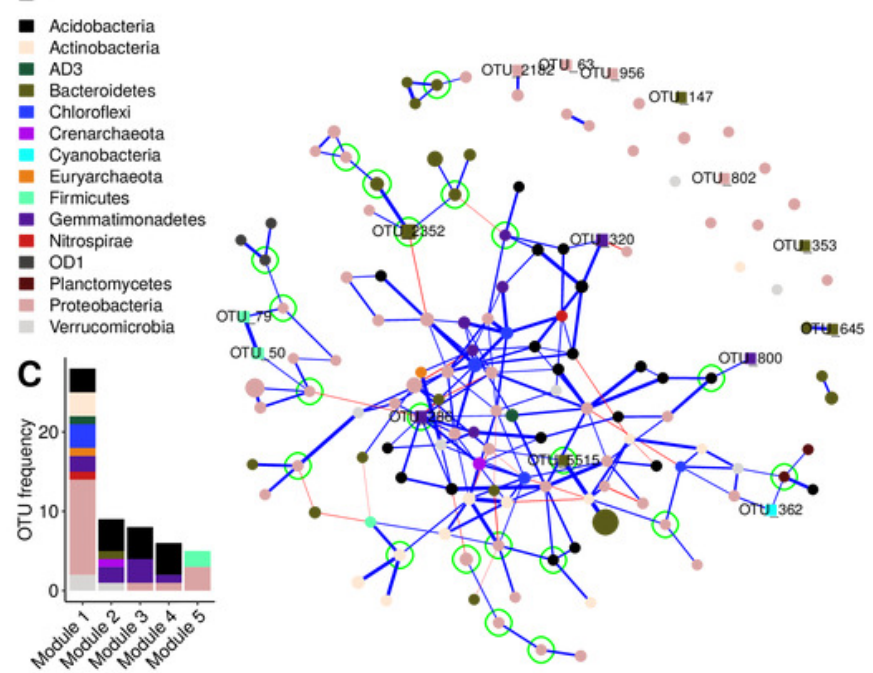




\section{Table $\mathbf{1}$ (on next page)}

Table 1 Mean OTU richness (S), Evenness (E), and Shannon diversity index (H) detected in the prokaryotic and fungal communities. Different letters represent statistically significant differences (Tukey test after ANOVA, $p \leq 0.05$ ).

Table 1 Mean OTU richness (S), Evenness (E), and Shannon diversity index (H) detected in the prokaryotic and fungal communities. Different letters represent statistically significant differences (Tukey test after ANOVA, $p \leq 0.05$ ). 
1 Table 1.

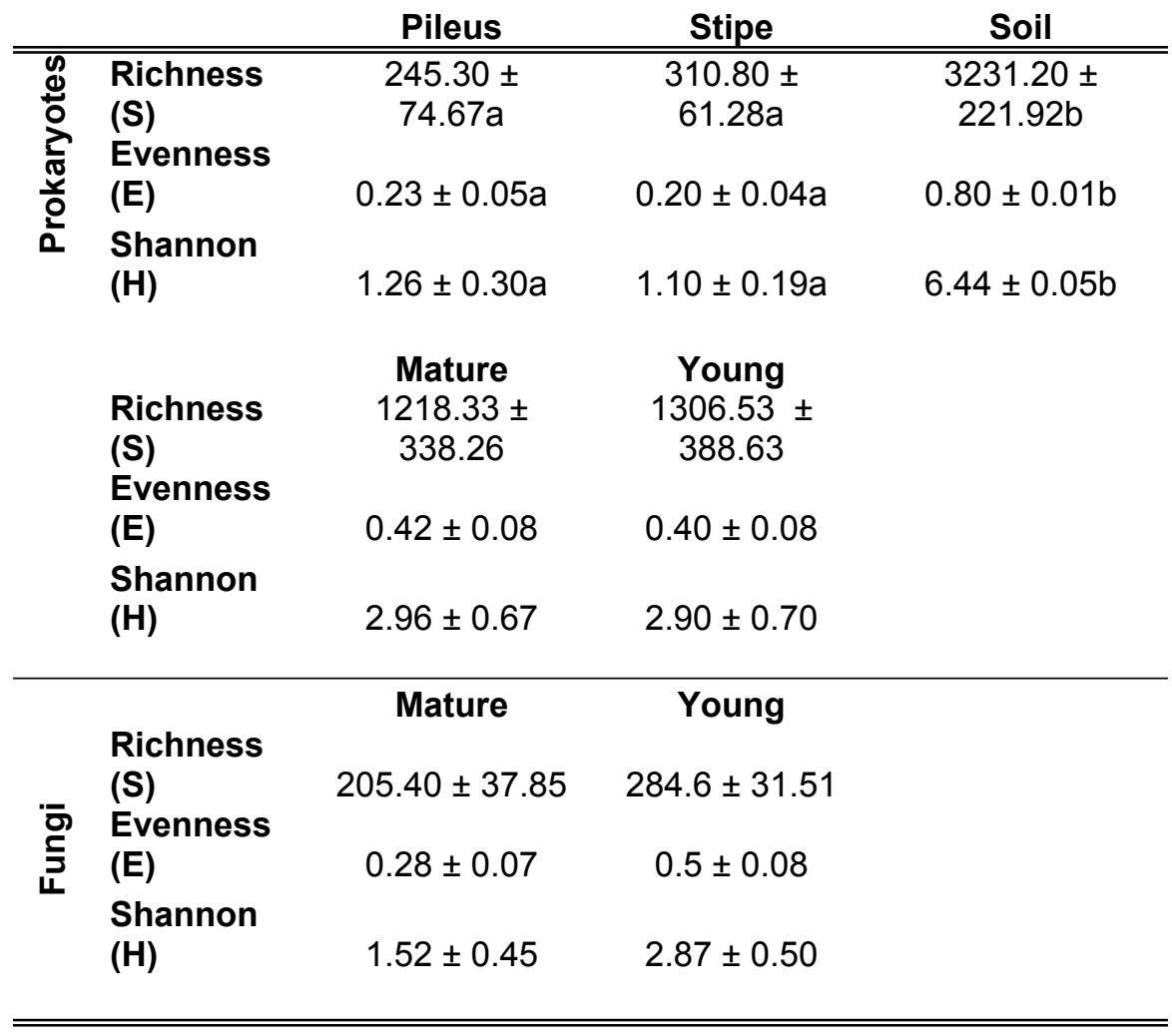

2 


\section{Table 2 (on next page)}

Table 2 Permutational multivariate analysis of variance (adonis) and multivariate homogeneity of groups dispersions analysis (betadisper) results for both prokaryotic and fungal communities associated with Morchella soil and fruiting bod

Table 2 Permutational multivariate analysis of variance (adonis) and multivariate homogeneity of groups dispersions analysis (betadisper) results for both prokaryotic and fungal communities associated with Morchella soil and fruiting bodies. Significant $p$-values at $p \leq 0.05$ are highlighted in bold. 
1 Table 2.

\begin{tabular}{|c|c|c|c|c|c|c|c|}
\hline & Factor & & PERI & ANOV & & DISPI & RSION \\
\hline & & Df & $\begin{array}{c}\text { F- } \\
\text { value }\end{array}$ & $\mathbf{R}^{2}$ & $\begin{array}{c}P- \\
\text { value }\end{array}$ & $\begin{array}{c}\text { F- } \\
\text { value }\end{array}$ & $\begin{array}{c}P- \\
\text { value }\end{array}$ \\
\hline & Stage & 1 & 1.156 & 0.022 & 0.297 & 0.618 & 0.438 \\
\hline 。ँ & Origin & 2 & 12.651 & 0.471 & 0.001 & 9.627 & $<0.001$ \\
\hline$\frac{\pi}{\pi}$ & Stage:Origin & 2 & 1.655 & 0.062 & 0.112 & & \\
\hline 흥 & Residuals & 24 & & & & & \\
\hline$\overline{0}$ & Total & 29 & & & & & \\
\hline & & Df & $\begin{array}{c}\text { F- } \\
\text { value }\end{array}$ & $\mathbf{R}^{2}$ & $\begin{array}{c}\text { P- } \\
\text { value }\end{array}$ & $\begin{array}{c}\text { F- } \\
\text { value }\end{array}$ & $\begin{array}{c}P- \\
\text { value }\end{array}$ \\
\hline & Stage & 1 & 0.698 & 0.432 & 0.027 & 0.011 & 0.917 \\
\hline$\Xi$ & Residuals & 8 & & & & & \\
\hline & Total & 9 & & & & & \\
\hline
\end{tabular}

2 


\section{Table 3 (on next page)}

Table 3 List of the top abundant bacterial genera associated to fungal fruiting bodies of different fungal taxa found in this study and from the literature.

Table 3 List of the top abundant bacterial genera associated to fungal fruiting bodies of different fungal taxa found in this study and from the literature. 
Table 3

\begin{tabular}{|c|c|c|c|c|c|}
\hline Family & Fungal species & Bacterial genera & $\begin{array}{l}\text { Isolation } \\
\text { method }\end{array}$ & Origin & Reference \\
\hline Agaricaceae & $\begin{array}{l}\text { Agaricus } \\
\text { bisporus }\end{array}$ & $\begin{array}{l}\text { Microbacterium, } \\
\text { Pseudomonas, Ewingella, } \\
\text { Enterobacter }\end{array}$ & $\begin{array}{l}\text { culture } \\
\text { dependent }\end{array}$ & Pileus/Stipe & $\begin{array}{l}\text { Ali Aslani et al., 2018; } \\
\text { Rossouw \& Korsten, } \\
2016\end{array}$ \\
\hline Amanitaceae & Amanita spp. & $\begin{array}{l}\text { Pseudomonas, } \\
\text { Janthinobacterium, } \\
\text { Enterobacter, Burkholderia, } \\
\text { Acinetobacter }\end{array}$ & $\begin{array}{l}\text { culture } \\
\text { independent }\end{array}$ & Pileus/Stipe & $\begin{array}{l}\text { Pent et al., 2017; Liu et } \\
\text { al., } 2017\end{array}$ \\
\hline Boletaceae & Leccinum spp. & $\begin{array}{l}\text { Burkholderia, } \\
\text { Chryseobacterium, } \\
\text { Novosphingobium }\end{array}$ & $\begin{array}{l}\text { culture } \\
\text { independent }\end{array}$ & Pileus/Stipe & Pent et al., 2017 \\
\hline Chantarellaceae & $\begin{array}{l}\text { Chantarellus } \\
\text { spp. }\end{array}$ & $\begin{array}{l}\text { Chitinophaga, Rhizobium, } \\
\text { Bacteroides, Hafnia, } \\
\text { Enterobacter }\end{array}$ & $\begin{array}{l}\text { culture } \\
\text { independent }\end{array}$ & Pileus/Stipe & $\begin{array}{l}\text { Pent et al., 2017; Kumari } \\
\text { et al., } 2013\end{array}$ \\
\hline \multirow{3}{*}{ Morchellaceae } & $\begin{array}{l}\text { Morchella } \\
\text { sextelata }\end{array}$ & $\begin{array}{l}\text { Pedobacter, Pseudomonas, } \\
\text { Stenotrophomonas, } \\
\text { Flavobacterium }\end{array}$ & $\begin{array}{l}\text { culture } \\
\text { independent }\end{array}$ & Pileus/Stipe & This study \\
\hline & $\begin{array}{l}\text { Leucangium } \\
\text { carthusianum }\end{array}$ & $\begin{array}{l}\text { Pseudomonas, } \\
\text { Jantinobacterium }\end{array}$ & $\begin{array}{l}\text { culture } \\
\text { independent }\end{array}$ & Gleba & Benucci \& Bonito, 2016 \\
\hline & $\begin{array}{l}\text { Kalapuya } \\
\text { brunnea }\end{array}$ & $\begin{array}{l}\text { Jantinobacterium, } \\
\text { Flavobacterium, Rhizobium, } \\
\text { Pseudomonas }\end{array}$ & $\begin{array}{l}\text { culture } \\
\text { independent }\end{array}$ & Gleba & Benucci \& Bonito, 2016 \\
\hline Russulaceae & Lactarius rufus & $\begin{array}{l}\text { Burkholderia, Shewanella, } \\
\text { Dyella }\end{array}$ & $\begin{array}{l}\text { culture } \\
\text { independent }\end{array}$ & Pileus/Stipe & Pent et al., 2017 \\
\hline Suillaceae & Suillus bovinus & $\begin{array}{l}\text { Burkoholderia, } \\
\text { Corynebacterium, } \\
\text { Pseudomonas }\end{array}$ & $\begin{array}{l}\text { culture } \\
\text { independent }\end{array}$ & Pileus/Stipe & Pent et al., 2017 \\
\hline Tuberaceae & Tuber borchii & $\begin{array}{l}\text { Sinorhizobium/Ensifer, } \\
\text { Bradyrhizobium, Rhizobium, } \\
\text { Microbacterium }\end{array}$ & $\begin{array}{l}\text { culture } \\
\text { dependent }\end{array}$ & Gleba & $\begin{array}{l}\text { Barbieri et al., 2005; } \\
\text { Splivallo et al., } 2015\end{array}$ \\
\hline
\end{tabular}




\begin{tabular}{|c|c|c|c|c|c|}
\hline & $\begin{array}{l}\text { Tuber } \\
\text { aestivum }\end{array}$ & $\begin{array}{l}\text { Bradyrhizobium, } \\
\text { Polaromonas, Pseudomonas }\end{array}$ & $\begin{array}{l}\text { culture } \\
\text { independent }\end{array}$ & Gleba & Splivallo et al., 2019 \\
\hline & $\begin{array}{l}\text { Tuber } \\
\text { magnatum }\end{array}$ & $\begin{array}{l}\text { Sinorhizobium, } \\
\text { Bradyrhizobium, Rhizobium, } \\
\text { Variovorax }\end{array}$ & $\begin{array}{l}\text { culture } \\
\text { dependent }\end{array}$ & Gleba & $\begin{array}{l}\text { Amicucci et al., 2018; } \\
\text { Barbieri et al., } 2007\end{array}$ \\
\hline & $\begin{array}{l}\text { Tuber } \\
\text { melanosporum }\end{array}$ & $\begin{array}{l}\text { Bradyrhizobium, } \\
\text { Polaromonas, Variovorax, } \\
\text { Propionibacterium }\end{array}$ & $\begin{array}{l}\text { culture } \\
\text { independent }\end{array}$ & Gleba & $\begin{array}{l}\text { Antony-Babu et al., } \\
\text { 2014; Benucci \& Bonito, } \\
2016\end{array}$ \\
\hline Tricholomataceae & $\begin{array}{l}\text { Tricholoma } \\
\text { matsutake }\end{array}$ & $\begin{array}{l}\text { Pseudomonas, Serratia, } \\
\text { Mycetocola, Ewingella, } \\
\text { Stenotrophomonas }\end{array}$ & $\begin{array}{l}\text { culture } \\
\text { dependent }\end{array}$ & Pileus/Stipe & Oh et al., 2018 \\
\hline
\end{tabular}

